\title{
Accounting And Financial Practice And Research In The Era Of Big Data
}

\author{
${ }^{1}$ Jesus Vargas, ${ }^{2}$ Herbert Víctor Huaranga Rivera ${ }^{[0002-8054-4213]}$, ${ }^{3}$ Mohammad Haroun Sharairi ${ }^{\text {[0000- }}$ \\ ${ }_{0002-0312-7977]}{ }^{4}$ Ricardo F. Cosio Borda ${ }^{[0000-0002-1765-097 X]},{ }^{5}$ Alberto Clavería Navarrete ${ }^{[0000-0002-4957-7738]}$ \\ ${ }^{1}$ Universidad de la Costa, Barranquilla, Colombia \\ ${ }^{2}$ Universidad Nacional Intercultural de la Selva Central Juan santos Atahualpa, Perú, \\ ${ }^{3}$ Assistant Professor, College of Business, Al Ain University, UAE. \\ ${ }^{4}$ Universidad Autónoma del Perú, Lima, Perú and Universidad Privada del Norte, Lima, Perú. \\ ${ }^{5}$ Universidad de Sevilla, España \\ 1*jvargas41@ @uc.edu.co, ${ }^{2}$ hhuaranga@ uniscjsa.edu.pe, ${ }^{3}$ mohammad.sharairi@aau.ac.ae, \\ 4ricardo.cosio@ autonoma.pe, ${ }^{5}$ claveria.alberto@gmail.com
}

Article History: Received: 11 January 2021; Accepted: 27 February 2021; Published online: 5 April 2021

\begin{abstract}
The purpose of the study is to present a snapshot of big data academic research in accounting and finance, and to highlight the applications in the organization. The analysis is conducted through information provided by Scopus in the period 2016-2020. Relevant literature is identified and sampled to derive a taxonomy of topics, which are studied from the perspective of a taxonomy of topics. These topics are studied from a quantitative perspective by identifying the volume of scientific production in different parameters such as year of publication, area of knowledge, author or authors, and qualitative by highlighting the analysis of the position shown by different research papers referring to the topic related above. This will help to answer the research question How is the accounting and financial practice and research through the analysis of Big data in the period 2016-2020?
\end{abstract}

Keywords: Finance, accounting, big data.

\section{Introduction}

The use of large volumes of information from any activity that traditional systems cannot process, store or analyze is known as Big Data, often defined by what are called the three V's (Volume, Velocity, Variety), which are characteristics of the type of data being processed through Big Data techniques(Tascón \& Coullaut, 2016).

In the organization, the use of big data techniques for information processing facilitates its handling and combination with traditional data to achieve the greatest possible efficiency in decision making(Joyanes Aguilar, 2013).

It should be noted that the management of large volumes of information is a challenge for companies, and its processing demands equally large efforts, but the management that can be given to the data begins according to its initial classification, which can be divided into two large groups, structured and unstructured data. The first group is traditional data that are collected through fixed formats such as those that are filled out to know the date of birth, identification number, telephone number, of a certain group of people. On the other hand, the second group corresponds to data that lack a specific or fixed format for their management, such as audios, photographs, texts, among others.

In accounting and finance, having an efficient information system is vital for the good management of resources and decision making, and this system is nourished with data susceptible to analysis, which is the main function of several big data tools. The data is processed through these tools and in the process of classification and analysis becomes vital information for the board of directors of any organization. For this reason, the purpose of this study is to analyze the current state of research on Big Data, accounting and finance variables by analyzing data derived from the Scopus platform in the period 2016-2020.

\section{General Objective}

To describe the accounting and financial practice and research from a quantitative approach through a bibliometric analysis, and qualitative through the study of the bibliography registered in the period 2016-2020.

\section{Methodology}

This research work will propose a study with a bibliometric approach and analysis of the bibliography found in the Scopus database on papers whose object of study is the application of Big Data techniques in the area of finance and accounting to know the current status of the theories that are being implemented in a present where it is increasingly necessary to study large volumes of data from its conception to the application of strategies derived from the interpretation of the same, in order to answer the question How is the accounting and financial practice and research in the era of Big Data? 


\subsection{Methodological design}

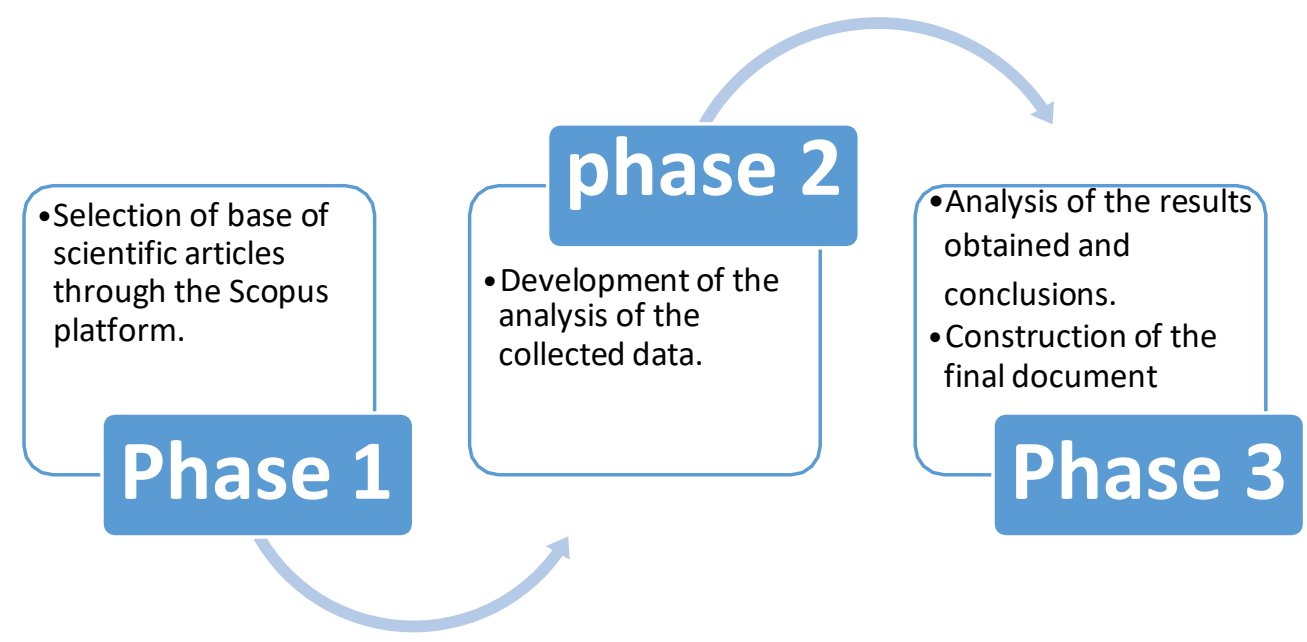

Chart 1. Methodological Design

Source:(Viloria, Vargas, \& Garcia, 2019)

\subsubsection{Phase 1: Selection of Papers}

The purpose of the first phase is to select the list of papers that will be subjected to their respective analysis in order to evaluate their level of impact on the achievement of the objective, which will be chosen taking into account the following search parameters in the Scopus database:

- $\quad$ Papers whose variables of study are Accounting, Finance and Big data.

- $\quad$ Papers published within the period 2016-2020 without distinction of country of origin.

- $\quad$ Papers published in journals indexed in the Scopus database.

- $\quad$ Papers published in the area of Business Sciences.

Applying the above search parameters, the result obtained is a total of 9150 scientific papers that comply with the same parameters.

\subsubsection{Phase 2: Data analysis}

Through the execution of the second phase, the data collected in the previous phase are distributed in order to perform an analysis of different aspects to be taken into account, such as year of publication, area of knowledge, author(s), country of origin and type of research. It should be noted that this analysis is carried out through a bibliometric approach to know the quantitative perspective of the development of the practice and research of the variables under study, as well as from a qualitative perspective to understand the present of the bibliography identified as study material for the fulfillment of the stated objective.

3.1.3 Phase 3: Analysis of results, and construction of the final report.

To conclude this study, in phase 3 the results are analyzed through the graphs derived from the classification by categories that help in the qualitative and quantitative analysis, conclusions and drafting of the final document.

\section{Discussion of results.}

After the execution of the search parameters within the Scopus database, a large number of publications whose variable of study is accounting, finance and Big Data are found. A total of 9150 papers that are framed within the study of business sciences during the period 2016-2020 and constitute the raw material of the present research. 
${ }^{1}$ Jesus Vargas Villa, ${ }^{2}$ Huaranga Rivera, Herbert Víctor, ${ }^{3}$ Mohammad Haroun Sharairi, ${ }^{4}$ Ricardo F. Cosio Borda, ${ }^{5}$ Alberto Clavería Navarrete

\subsection{Distribution of papers by area of knowledge}

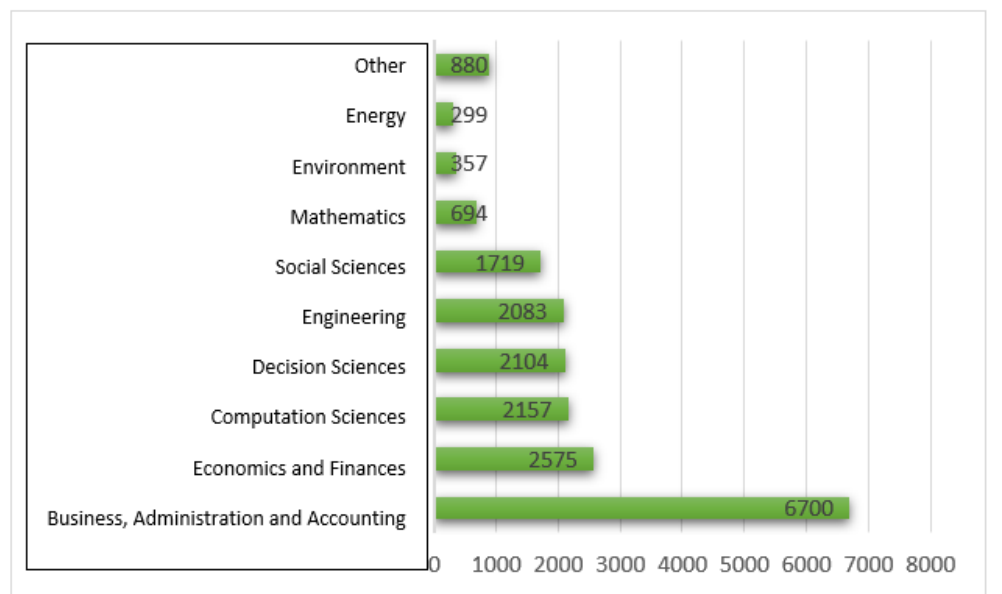

Chart 2. Distribution of papers by area of knowledge.

Source: Own elaboration (2021); based on the data provided by SCOPUS.

Although this study focuses on all the existing production within the area of business sciences, it is important to distinguish the disciplines that are developed within this area, as well as studies carried out in other areas, but focused on the organization. Figure 2 shows which are the most outstanding ones.

It is evident that the main disciplines of the business sciences such as Business, Management and Accounting report a total of 6,700 papers published in high impact journals, $34.3 \%$, which represents a high participation in the total number of products in the aforementioned period.

Among the papers registered by this discipline is the research work "An application on building information model to procurement strategy of copper raw material with big data analytics" which addresses the issue of price fluctuation analysis in raw material for construction through Big Data mechanisms, to help the organization to find the key factors in the price dynamics in the market and somehow predict the variations and take advantage of the best prices in advance in order to optimize resources ( $\mathrm{Li}$, Chiu, \& Chiu, 2020). In this way, it can be demonstrated how data analysis through the tools offered by Big Data, can help an organization in meeting its objectives, in this case financial and cost. This helps in the positioning and competitiveness of the company in the market where it operates.

Following the aforementioned discipline, there are areas such as Economics and Finance and Computer Science that participate in this list with a total of 2,575 (13.4\%) and 2,157 (11.2\%) papers respectively, and although the latter is not part of the considered Business Sciences, it does address the topic of Big Data as it is a subject that is generally studied in Computer Science due to all the technological demands involved in the design and implementation of Big Data tools. For example, the paper "Big data and firm performance: The roles of market-directed capabilities and business strategy" is registered within this discipline, which performs an indepth analysis of the investments made on Big Data tools for the positioning of the organization through marketing strategies. For this reason, the multidisciplinary nature of the study is shown in relation to the management of large amounts of information and how the latter is vital today for, through its correct analysis, effective decision making.

\subsection{Distribution of papers by year of publication.}

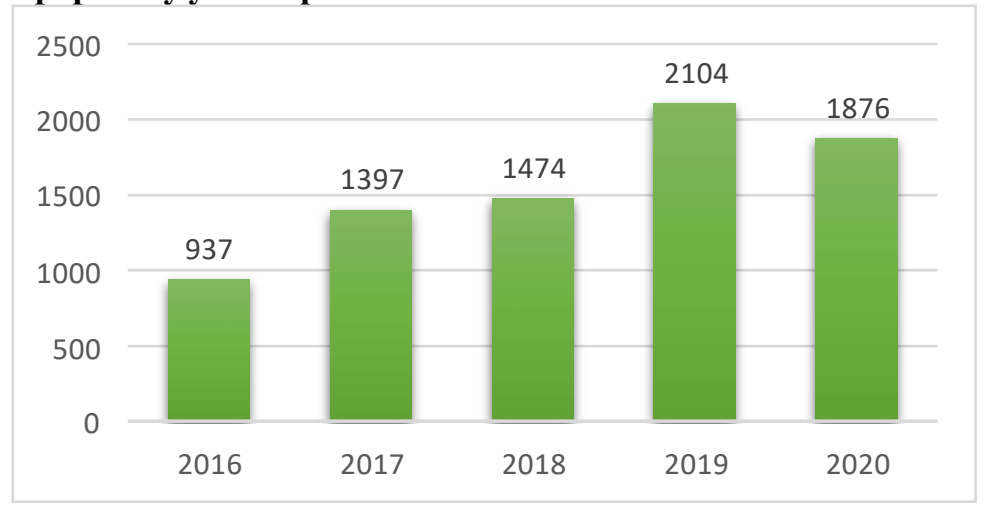

Chart 3. Distribution of papers by year of publication. 
For the analysis of the distribution by year of publication, it is important to note that the period 2016-2020 was chosen to obtain current results and measure in a simpler way the growth of the production of papers under the variables finance, accounting and Big Data.

A sustained growth is evidenced between the years 2016 and 2019 being the latter year when more publications were registered in Scopus database, reaching a total of 2,104 research papers that meet the search parameters applied in the present research. Followed by 2020 with 1,876 papers.

From the above it is concluded that as technologies advance in terms of processing large volumes of data, so does the interest on the part of organizations, to implement any number of tools that are possible in the different areas of the companies, in order to optimize costs, time, effort and others that provide stability in decision making and therefore an increase in the profitability of their exercises and positioning in the market.

Proof of this is shown in the 2018 paper "Big data analytics: Understanding its capabilities and potential benefits for healthcare organizations" as organizations, in this case healthcare, begin to take an interest in the use of Big Data analytics to improve the quality in the delivery of their services, as well as studying the benefits that are acquired by conducting studies of unstructured data through Big Data tools and mechanisms (Wang, Kung, \& Byrd, 2018). This paper has been cited 370 times since its publication and has been a key piece in the development of the following research that has sought to improve decision making in different areas of health sector organizations, through Big Data analysis.

4.3 Distribution of papers by author $(\mathrm{s})$.

At this point, the frequency with which one or more authors have published their research papers under the variables referenced above is analyzed in order to know the performance and evolution of their studies during the period 2016-2020.

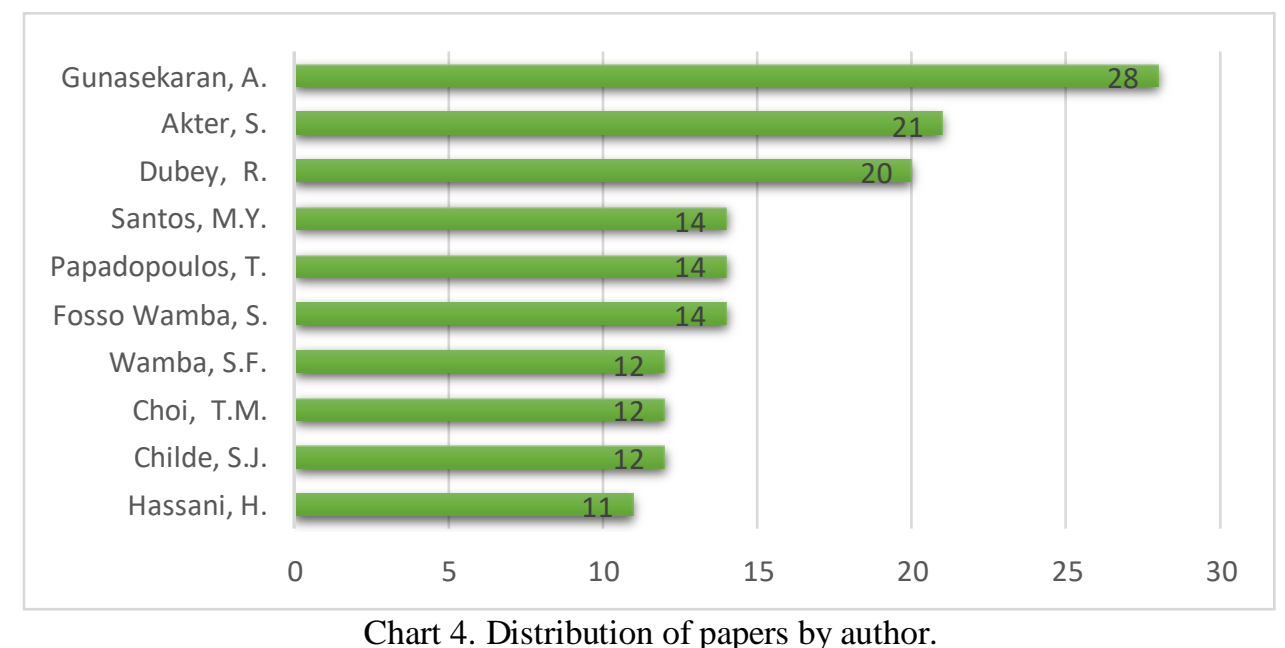

Chart 4. Distribution of papers by author.

Source: Own elaboration (2021); based on data provided by SCOPUS.

Chart 4 shows Angappa Gunasekaran with the highest number of papers under his authorship with a total of 28 research papers with affiliation to California State University, Bakersfield in the United States. Among his papers, the most cited by other authors is the paper "Big data analytics in logistics and supply chain management: Certain investigations for research and applications" was mentioned in other research papers 465 times and describes how technological growth has forced companies to become interested in the study of big data, and the application of strategies throughout the supply chain, so it is important material for any research that seeks to explain the usefulness of the analysis of large amounts of data and the application of strategies derived from the study of big data in all business activities (Wang, Gunasekaran, Ngai, \& Papadopoulos, 2016).

Similarly, authors such as Akter, Shahriar and Dubey, Rameshwar are in second and third place with 21 and 20 publications respectively. Of the latter, publications such as "Modelling quality dynamics, business value and firm performance in a big data analytics environment" stand out with 109 citations in total and explain how quality dynamics in the big data environment is related to the improvement of business value and company performance(Dubey, Fosso Wamba, Ji-Fan Ren, Akter, \& Childe, 2017). The study, co-authored by Fosso Wamba among other authors, who recorded a total production of 12 research papers under the variables under study, reveals the relationship between quality improvement in different processes and big data analysis. 
${ }^{1}$ Jesus Vargas Villa, ${ }^{2}$ Huaranga Rivera, Herbert Víctor, ${ }^{3}$ Mohammad Haroun Sharairi, ${ }^{4}$ Ricardo F. Cosio Borda, ${ }^{5}$ Alberto Clavería Navarrete

\subsection{Distribution of papers by country of origin.}

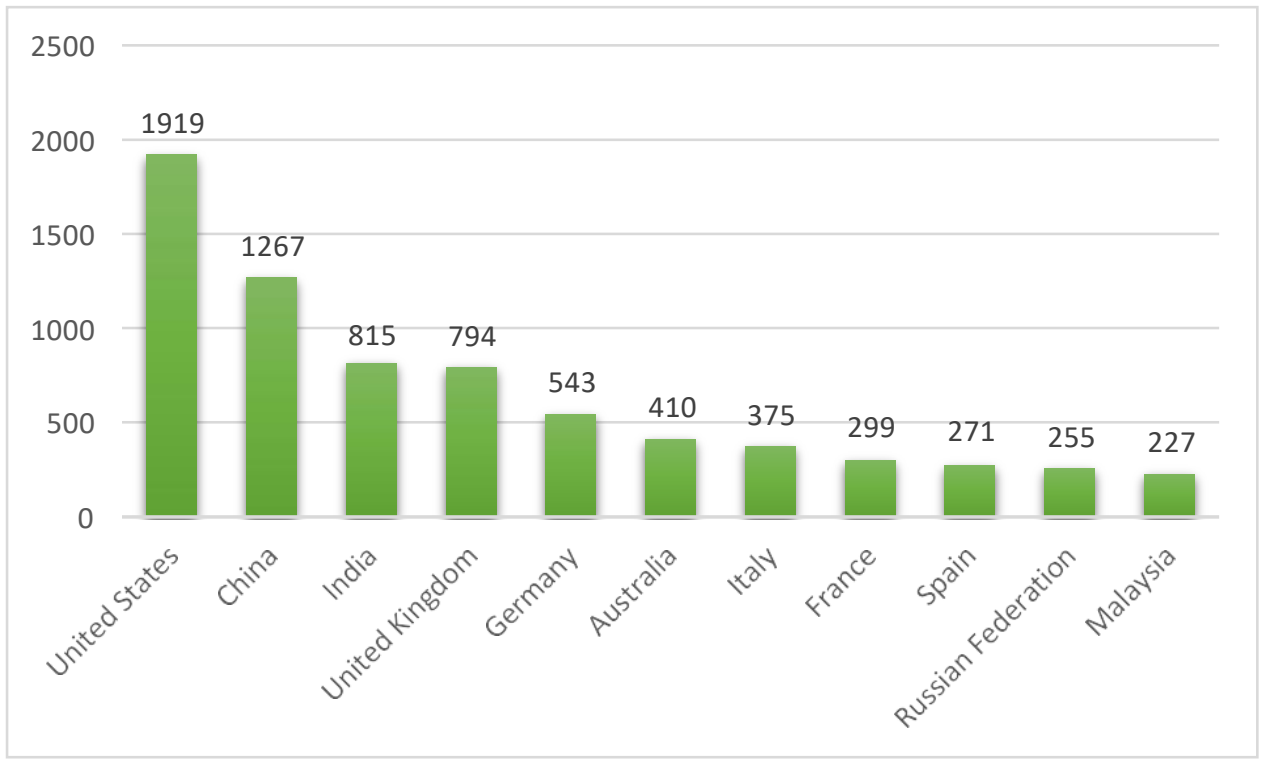

Chart 5. Distribution of papers by country of origin.

Source: Own elaboration (2021); based on data provided by SCOPUS.

Chart 5 shows which countries lead the production of scientific papers that study Big Data analysis focused on the different areas of the organization, and shows that the United States, with a total of 1,919 research papers, is the country that is carrying out the most studies of this type. This is followed by two Asian countries, China and India, with 1,267 and 815 articles published in high-impact journals, respectively. Although the graph shows the first eleven positions in terms of production volume, it is worth mentioning that Latin American, African and Oceanic countries have also historically participated with scientific production focused on the topic under study, such as Brazil with 155 papers, South Africa with 128 and New Zealand with 75.

\section{Conclusions}

The study framed in the analysis of Big Data focused on the different areas of the organization, such as finance, accounting, marketing, among others, reveals how beneficial it can become in decision making and quality improvement in each process of the companies. It is evident through the analysis of the different works related in this study, that the significant advantages of studying the different options offered by a correct analysis with Big Data tools for big data, are greater compared to the traditional processing of information, and how after the technological advances in the era of Big Data, has forced organizations in different economic sectors, to invest resources and efforts in training and indoctrination of practices related to the analysis of large amounts of data.

Currently, companies analyze consumer behavior through the analysis of structured and unstructured data, which yield valuable information for decision making and design of strategies for the optimization of financial resources in terms of investment. This implies a more effective methodology when measuring the effects of the implementation of organizational policies that seek to increase profitability and therefore competitiveness in a market with increasing demands and complexities.

\section{References}

1. Dubey, R., Fosso Wamba, S., Ji-Fan Ren, S., Akter, S., \& Childe, S. J. (2017). Modelling quality dynamics, business value and firm performance in a big data analytics environment. International Journal of Production Research, 5011-5026.

2. Joyanes Aguilar, L. (2013). BIG DATA, Analisis de grandes volumenes de datos en organizaciones. Mexico : ALFAOMEGA.

3. Li, S.-T., Chiu, K.-C., \& Chiu, T.-H. (2020). An Application on Building Information Model to Procurement Strategy of Copper Raw Material with Big Data Analytics. IEEE International Conference on Industrial Engineering and Engineering Management, 696-700. doi:10.1109/IEEM45057.2020.9309743

4. Tascón, M., \& Coullaut, A. (2016). Big Data y el internet de las cosas.Madrid: Catarata.

5. Viloria, A., Vargas, J., \& Garcia, E. (2019). Big data marketing during the period 2012-2019: a 
bibliometric review. International Conference on Intelligent Computing, Information and Control Systems, 186-193.

6. Wang, G., Gunasekaran, A., Ngai, W. T., \& Papadopoulos, T. (2016). Big data analytics in logistics and supply chain management: Certain investigations for research and applications. International Journal of Production Economics, 98-110.

7. Wang, Y., Kung, L., \& Byrd, T. A. (2018). Big data analytics: Understanding its capabilities and potential benefits for healthcare organizations. Technological Forecasting and Social Change, 3-13.

8. Dubey, R., Bryde, D. J., Foropon, C., Tiwari, M., Dwivedi, Y., \& Schiffling, S. (2020). An investigation of information alignment and collaboration as complements to supply chain agility in humanitarian supply chain. International Journal of Production Research, doi:10.1080/00207543.2020.1865583

9. Dubey, R., \& Gunasekaran, A. (2015). Education and training for successful career in big data and business analytics. Industrial and Commercial Training, 47(4), 174-181. doi:10.1108/ICT-08-2014-0059

10. Dubey, R., Gunasekaran, A., \& Childe, S. J. (2019). Big data analytics capability in supply chain agility: The moderating effect of organizational flexibility. Management Decision, 57(8), 2092-2112. doi:10.1108/MD-01-2018-0119

11. Dubey, R., Gunasekaran, A., Childe, S. J., Blome, C., \& Papadopoulos, T. (2019). Big data and predictive analytics and manufacturing performance: Integrating institutional theory, resource-based view and big data culture. British Journal of Management, 30(2), 341-361. doi:10.1111/14678551.12355

12. Dubey, R., Gunasekaran, A., Childe, S. J., Bryde, D. J., Giannakis, M., Foropon, C., . . Hazen, B. T. (2020). Big data analytics and artificial intelligence pathway to operational performance under the effects of entrepreneurial orientation and environmental dynamism: A study of manufacturing organisations. International Journal of Production Economics, 226 doi:10.1016/j.ijpe.2019.107599

13. Dubey, R., Gunasekaran, A., Childe, S. J., Luo, Z., Wamba, S. F., Roubaud, D., \& Foropon, C. (2018). Examining the role of big data and predictive analytics on collaborative performance in context to sustainable consumption and production behaviour. Journal of Cleaner Production, 196, 1508-1521. doi:10.1016/j.jclepro.2018.06.097

14. Dubey, R., Gunasekaran, A., Childe, S. J., Papadopoulos, T., Luo, Z., Wamba, S. F., \& Roubaud, D. (2019). Can big data and predictive analytics improve social and environmental sustainability? Technological Forecasting and Social Change, 144, 534-545. doi:10.1016/j.techfore.2017.06.020

15. Dubey, R., Gunasekaran, A., Childe, S. J., Roubaud, D., Fosso Wamba, S., Giannakis, M., \& Foropon, C. (2019). Big data analytics and organizational culture as complements to swift trust and collaborative performance in the humanitarian supply chain. International Journal of Production Economics, 210, 120-136. doi:10.1016/j.ijpe.2019.01.023

16. Dubey, R., Luo, Z., Gunasekaran, A., Akter, S., Hazen, B. T., \& Douglas, M. A. (2018). Big data and predictive analytics in humanitarian supply chains: Enabling visibility and coordination in the presence of swift trust. International Journal of Logistics Management, 29(2), 485-512. doi:10.1108/IJLM-022017-0039

17. Gunasekaran, A., Papadopoulos, T., Dubey, R., Wamba, S. F., Childe, S. J., Hazen, B., \& Akter, S. (2017). Big data and predictive analytics for supply chain and organizational performance. Journal of Business Research, 70, 308-317. doi:10.1016/j.jbusres.2016.08.004

18. Jeble, S., Dubey, R., Childe, S. J., Papadopoulos, T., Roubaud, D., \& Prakash, A. (2018). Impact of big data and predictive analytics capability on supply chain sustainability. International Journal of Logistics Management, 29(2), 513-538. doi:10.1108/IJLM-05-2017-0134

19. Ji-fan Ren, S., Fosso Wamba, S., Akter, S., Dubey, R., \& Childe, S. J. (2017). Modelling quality dynamics, business value and firm performance in a big data analytics environment. International Journal of Production Research, 55(17), 5011-5026. doi:10.1080/00207543.2016.1154209

20. Mishra, D., Luo, Z., Jiang, S., Papadopoulos, T., \& Dubey, R. (2017). A bibliographic study on big data: Concepts, trends and challenges. Business Process Management Journal, 23(3), 555-573. doi:10.1108/BPMJ-10-2015-0149 